\title{
Socioeconomic and Public Policy Impacts of China Pakistan Economic Corridor on Khyber Pakhtunkhwa
}

\author{
Shehryar Khan \\ School of Public Affairs, University of Science and Technology China \\ Hefei, Anhui, 230026, China \\ Tel: 86-156-6569-7157Ｅ-mail: shery359@mail.ustc.edu.cn
}

Guijian Liu (Corresponding author)

CAS Key Laboratory of Crust-Mantle Materials and the Environments

School of Earth and Space Science, University of Science and technology China

JinZai Road 96, Hefei, Anhui, China

State Key Laboratory of Loess and Quaternary Geology, Institute of Earth Environment

The Chinese Academy of Sciences, Xi'an, Shaanxi 710075, PR China

Tel: 86-551-360-3714Ｅ-mail: lgj@ustc.edu.cn

Received: October 10, 2018 Accepted: October 26, 2018 Published: January 23, 2018

doi:10.5296/emsd.v8i1.13758 URL: https://doi.org/10.5296/emsd.v8i1.13758

\begin{abstract}
The projects under CPEC specifically the Energy, Infrastructure and Economic zones development Promises significant implication for people of Pakistan. The aim of the study was top analyze the Impacts of CPEC on Socioeconomic, Public Policy, Environmental and Economic Indicators in Khyber Pakhtunkhwa. The study used $\mathrm{T}$ Test for the primary data collected from respondents of different Public Policy, Economic and Educational Departments in Khyber Pakhtunkwa (KPK). The results of the study support significant impacts of CPEC on Economic, Socioeconomic and Public Policy Indicators in KPK. The results also present some environmental challenges due to the CPEC project. It is concluded that health, education, business competitiveness, economic political stability will improve with the project. The Project is expected to improve the socioeconomic indicators of the underdeveloped Province of KPK. Further the Project will support the KPK Public Policy concerns such women empowerment, allocation of resources, economic stability and
\end{abstract}


increasing productivity to reduce poverty and inequality of wealth.

Keywords: CPEC, Khyber Pakhtunkhwa, Socioeconomic, Public Policy, Economic

\section{Summary}

China Pakistan Friendship has paved way for highly influential economic and business opportunities for the region. The China Pakistan Economic Corridor is one mega project Initiated by China with a cost of $\$ 46$ Billion to lay down a route to the deep sea waters at Gawadar. The project offers an opportunity to China to integrate with the international market at cost efficient route. The projects under CPEC specifically the Energy, Infrastructure and Economic zones development Promises significant implication for people of Pakistan. In this context this study analyzed the potential Economic, socioeconomic, public policy and Environmental impacts of CPEC on the north of Pakistan using the case of Khyber Pakhtunkhwa (KPK) Province. The study used a survey technique for collection of data from respondents closely associated with the different dimensions of the CPEC projects in KPK. A structure equation model was used to analyze the data of the study collected through questionnaire. The results of the SEM support the view that CPEC has significantly strong impacts on the economic, socioeconomic and Public policy concerns of KPK. The health, education, business competitiveness, economic political stability will improve with the project. The efficient allocation of resources and economic zones will increase job opportunities thus reducing poverty and inequality of wealth in the region. The project will also offer increase in participation of women and will enhance women empowerment in the region. The results however also highlight some environmental concerns for KPK as a result of CPEC projects.

\section{Introduction}

The effects of recent financial crisis have provided quite a number of reasons for development of regional and international infrastructure for global competitiveness. The regional and international infrastructure provide an opportunity for interconnecting the far and distant areas, thereby having significantly positive impacts on the socioeconomic indicators and public policy concerns of these regions. (Bhattacharyay, 2012) states that development of regional and international trade infrastructure reduces the socioeconomic gap between the different regions. The Pak China Economic Corridor CPEC is the development of warm water port in Gawadar South of Pakistan. The Gawadar port will be connected to Kashger the Farthest West Chinese city. In this context the CPEC presents an important opportunity for economic and social development of the different distant regions in Pakistan, also the Project is supposed to help Pakistan in solving their energy problems, for China the $\mathrm{CPEC}$ is expected to increase their regional influence, further consolidate their global presence and also securing the future roots for trade (Small, 2015).

The South Asia is considered as one of the least integrated region in the world and Pakistan holds an important geographical position in the cross roads. The CPEC project with an Investment of approximately $\$ 46$ Billion is a part of long term strategic partnership between Pakistan and China having a time frame of 2013 to 2030. Table 1 of the study below presents the allocation of the package to different sectors under CPEC. 


\section{Macrothink \\ Environmental Management and Sustainable Development \\ ISSN 2164-7682 2019, Vol. 8, No. 1}

Table 1. CPEC Package Financial Allocation

\begin{tabular}{|l|l|}
\hline Projects & US\$ Millions \\
\hline Energy & 33,793 \\
\hline Transport and Infrastructure & \\
\hline Roads & 6,100 \\
\hline Rail Network & 3,690 \\
\hline Mass Transit & 1,600 \\
\hline Gawadar Port & 786 \\
\hline Others & 44 \\
\hline Total & 46,013 \\
\hline
\end{tabular}

The CPEC has two important dimensions which include on one side the development of the Gawadar Port and on the other side the development of surface roads and other infrastructure from Gawadar to the Southwest of Pakistan to Xinjiang in the Northwest of China (Aqeel, 2016). The short Term Projects Under CPEC are expected to be completed by the end of 2017, the medium term projects will be completed by 2025 while the long term projects are expected to be completed by 2030 .

Under the CPEC project Pakistani officials has signed a 43 years lease for the Gawadar port with China, also 2300 acres of land for developing deep sea Economic Zone at Gawadar. 


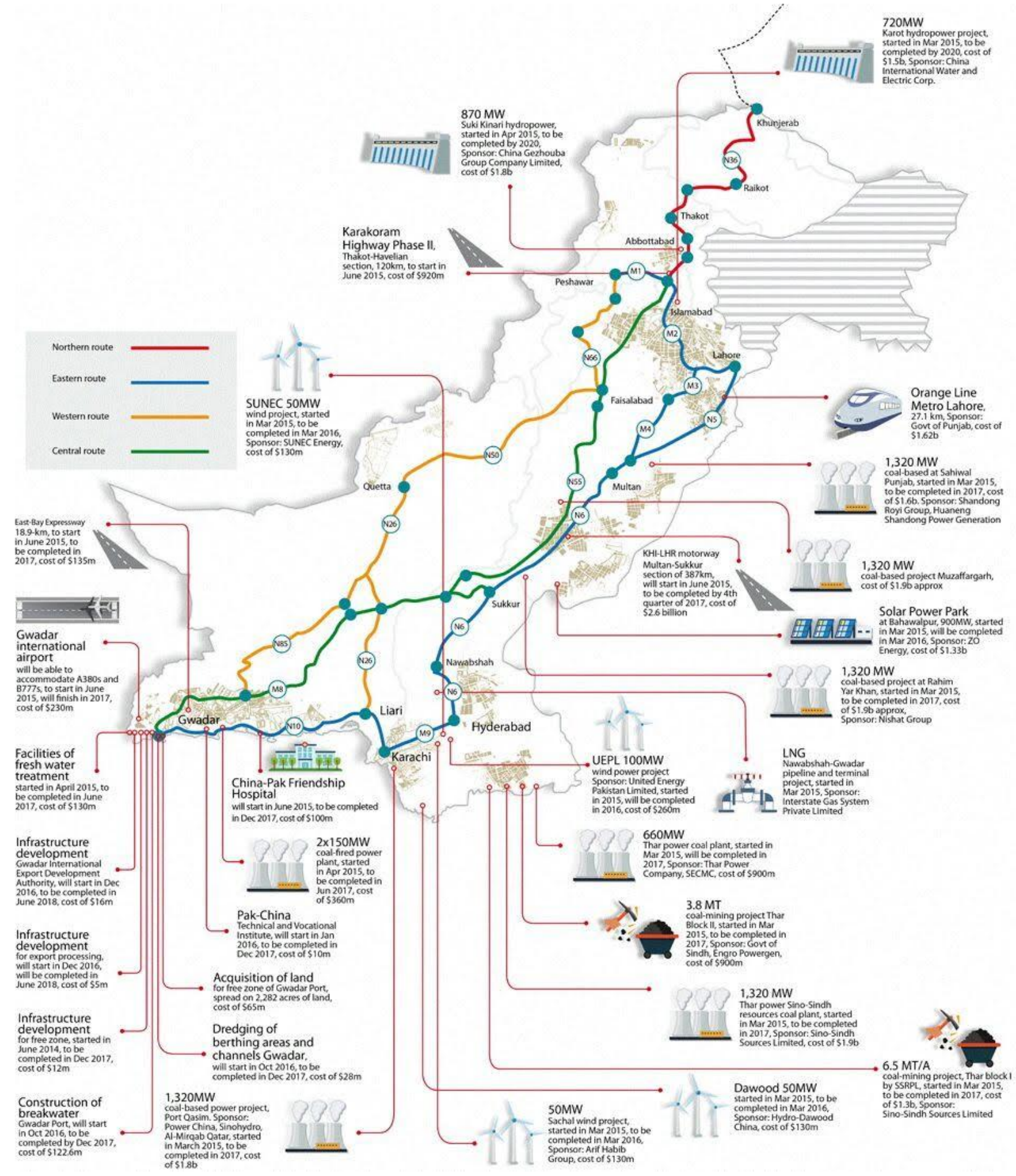

Figure 1. CPEC Projects

A summary of different projects under CPEC are provided in figure 1 of the study. The CPEC project is expected to drastically drop the cost of shipping of the Chinese trade and is also expected to drop the estimated shipment cost by 10 times (Aqeel, 2016,pp.106). The level of unemployment and disguised unemployment are rising simultaneously in Pakistan which has significantly increased the level of population in the poverty stratum. The objective of Sustainable Development can be attained by inclusive and sustainable economic growth 
through employment and entrepreneurship opportunities to eradicate poverty and hunger.

Employment opportunities, social welfare, women empowerment health and educational indicators are positively affected when public policies measures are undertaken to enhance the remunerative factors, skills and opportunities in the region. According to (UNDP, 2015) Pakistan is placed as 143 among 188 countries in the human development index however the current investment under CPEC is expected to increase the economic growth by 2 to $2.5 \%$ per year. The CPEC project specifically with the investment in infrastructure and energy is also expected to create more than 70000 new jobs in the region during 2013 to 2030. It is also expected that the infrastructure development under the CPEC will ease the access and decrease the cost of international trade and access to international and regional markets for the domestic producers that will further induce investment from private sector and increase productivity.

The CPEC is also expected to have positive impacts on the stock markets as well specifically the share prices of Cement and Steel sector will take a boost due to the heavy construction. The manufacturing sector in Pakistan will also take a boost from the increasing demand and availability of energy. The high level of demand and increasing income will also have positive impacts on the consumer stocks in Pakistan as well (Aqeel, 2016).

This study focuses on analyzing the impacts of CPEC on the economic and socioeconomic indicators in Pakistan along with the achievement of Public policy objectives and environmental impacts of CPEC. The socioeconomic and public policy impacts in the underdeveloped regions of Pakistan such as the north west Province of Pakistan namely Khyber Pakhtunkhwa (KPK) in terms of Health, education, employment opportunities and women empowerment is specifically focused in this study. The study provides significant insights for the Public policy makers to articulate policies that can enhance the socioeconomic indicators and social welfare of the people in KPK.

\subsection{Objectives of the Study}

The aim of the study is to analyze the impacts of CPEC on different economic, socioeconomic, public policy and environmental dimension in KPK Pakistan. The main objectives are as follow,

- To analyze the impacts of CPEC on Economic growth in KPK

- To find out the socioeconomic impacts of CPEC in KPK

- To analyze the achievement of Public Policy objectives with CPEC in KPK

- To find out the environmental impacts of CPEC in KPK

\section{Literature Review}

The transportation sector in an economy holds a key position for the internal growth, access to the markets and to put the host economy on trajectory of international trade. There are many means to achieve these objectives and Ports provide one such option which interconnects the land and deep sea routes. In a nutshell deep sea ports are considered the most cost effective sources of transportation in international and regional trade (Bengali, 
2015). The sea ports beside their implications for the economic arena of the area have also significant impacts on the societal and public stakes of the host.

The China Pakistan Economic Corridor will offer an opportunity to interconnect Pakistan, China, Africa and Middle East. Oil from the Middle East will be offloaded at the Gawadar port, which is located at the face of Persian Gulf and will be transported to China; this in consequence will reduce the transportation distance for oil imports of China by almost 12000 Kilometer (Habib et al, 2016). The Asian Development Bank report describes CPEC as an interconnection of economic agents along a geographic line as a connector between the economic nodes and hubs, which are mostly centered in urban lands where the economic actors and resources are mostly concentrated (Hamid, et al., 2012). In the Era of Globalization and the paradigm shift from security concerns to economic objectives, has necessitated the need of more interconnectivity of regional and international players through secure and cost efficient routes Gilbert and (Nilanjan, 2012). In this regard the term "Greater South Asia" is debated for the last few decades which encompasses Pakistan, China, Iran, and Afghanistan and all the way stretches to Myanmar. Beside the benefits for China from CPEC, Pakistani economy and Public policy objectives are also expected to benefit a great deal from the projects under CPEC by uplifting the economic and societal stakes of people in Pakistan (Xie et al., 2015).

The CPEC once functional will to a great extent change the economic and societal trajectory of the people falling at different routes and economic zones under CPEC (Hussain, et al., 2015). The most significant expectation from CPEC for the Policy makers in Pakistan is that CPEC will provide significant opportunities to marginalized regions of Pakistan that will help in eradicating the sense of deprivation and discrimination among these communities along with uplifting the socio economic dimensions (Midgley, 2013).

Public health and education are importantly influenced by traveling time and mobility of the people. Howard and (Masset, 2004) suggested that in developing countries convenient mobility and reduction in traveling time enhance enrolment rates. (Mattson, 2011) found that reduction in traveling time and ease In mobility enhance the access of general public to the utilization of health care and better educational facilities. Keeping the CPEC scenario in mind, (Habib et al., 2016) conducted a study in eleven district situated near to western route to analyze the effect of time reduction in traveling time and ease in mobility on education and health sector. The study found that the number of enrollment and attendance in school has shown significant increase and he also observed and argue that there is a significant increase in lady health worker utilization.

Hussain et al., 2015) found that CPEC enhance social interaction among people. It will create new economic opportunities for Pakistan which will bring more prosperity and economic development in Pakistan as well as china. The master plan has been prepared for CPEC in 2015 for four major areas of cooperation, i.e., energy, transport, infrastructure and industrial cooperation. It is also the part of master plan that china will take the initiative of building the Silk Road, which would be consider an economic belt between Pakistan and china. The initiative of Silk Road will not only accelerate the development of Pakistan and china but it 
will also enhance the development of global economy (Xudong, 2015).

(Haris, 2015) investigated that industrialization along CPEC in a special economic zone will help in the rehabilitation of deteriorated industrial units of Pakistan. (Tong, 2015) argues that this industrialization will create more employment opportunities for the local community rather than china or any other province of Pakistan. It is also examined that due to so many projects through CPEC a massive number of employment opportunities will take place. Pakistan has to seek protections plans for its domestic industries because of smaller economy as compared to china, (Hamid et al., 2012).

While discussing three routes disputation of CPEC, (Bengali, 2015) examined that deficiency of access to employment and to markets, socialization and health opportunities defined as regional inequality in some areas, initiate the basis for insurgency and disaffection; shaping the condition in which higher security costs is required. He has also compared these three routes in term of cost for which a comparative opportunity cost has been calculated by using three variables: output of four major corps, total area under cultivation and population density. He found that the western rout is the shortest and also bearing the least cost in terms of dislocation compensation cost and comparative opportunity cost. To estimate annual growth rates for the next decade a newly updated measure has been used and the result shows that growth rate will be higher because the production capability of Pakistan and gain from these capabilities is expected to be increase in the next decade. The estimated annual growth for the next decade is 5.07 percent for Pakistan. It was also found that countries located in south Asia and East Arica have the greatest potential for massive number of economic activities which will result in higher growth rate. (CID, 2016).

(Gilbert et al., 2012) conducted a study to analyze the relationship between transportation infrastructure and GDP. He found that efficient and well organized transportation infrastructure and system would boost GDP. It is believed that the highest increase in growth rate would be 14.8 percent in Nepal as a percentage of the current GDP, followed by Bangladesh with 4.10 percent and Sri Lanka 4.6 percent. It was also found that the growth rate of India would expect to be higher, by over $\$ 4.3$ billion and followed by Pakistan with $\$ 2.6$ billion. There will be a positive effect on the welfare of household through with clear outcomes of pro-poor in the region and cost reduction in regional transportation. The enhancement in welfare facilities in Pakistan as well as in south Asian countries would have positive impacts on the life of the households and would also help in reducing poverty level in these countries.

(Hussain et al., 2015) examined that CPEC is more than just a road because it will bring a wide level of connectivity via roads, pipelines, railway and special economic zones etc. They also observed that South Asian countries are least integrated countries with each other in the world. So CPEC is a big hope to integrate Pakistan with other South Asian countries and to connect the western part of china with Pakistan and also providing nearby routes to china for oil imports (Xie et al., 2015).

It can be concluded from the above discussion that CPEC project would enhance the social and economic of people in Pakistan, through using their productive capabilities and gain from 
it, reducing traveling time, easy mobility and employment generation, etc.

\section{Theoretical Framework}

The main aim of the study is to analyze the impacts of CPEC on the socioeconomic, public policy and Environmental dimensions in KPK Pakistan. The study used economic, socioeconomic, Public Policy concerns and Environmental impacts as the dependent variables of the study and CPEC is used as the dependent variables in the analysis. (Aqeel, 2016) presents that the CPEC provide significant opportunities for distant regions in Pakistan to develop their socioeconomic and Public policy indicators. The following figure presents the theoretical Model of the study.

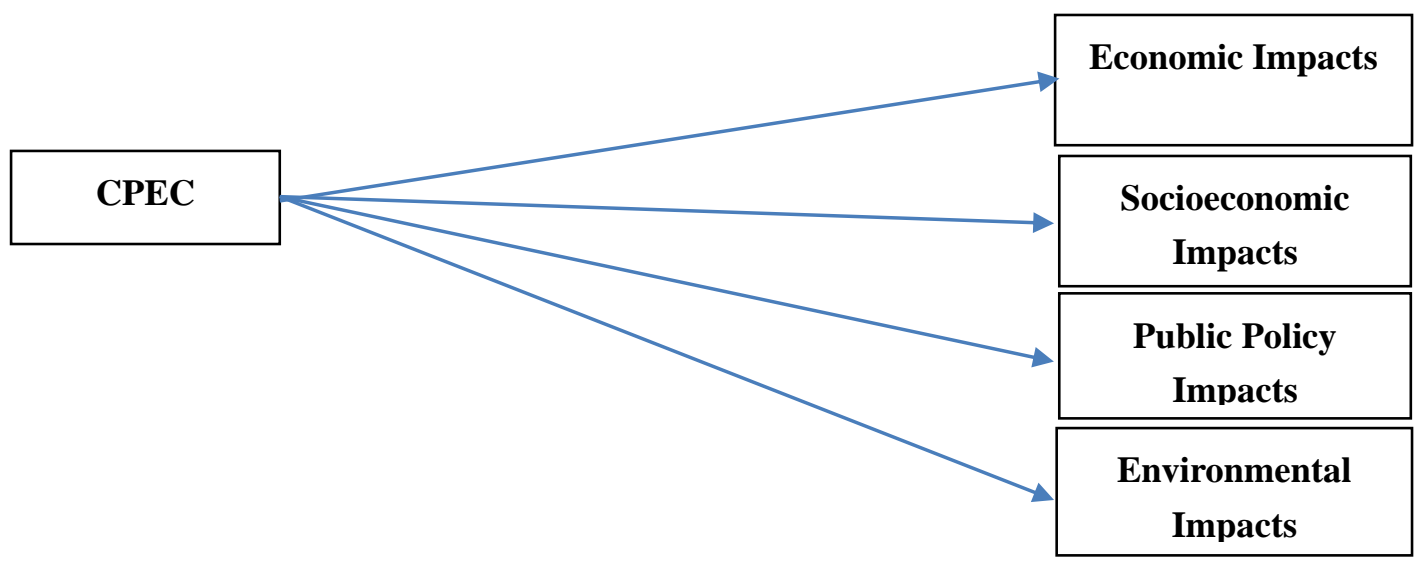

Figure 2. Theoretical Framework

In the figure given above CPEC project with the $\$ 46$ billion is regarded as the dependent variable in the analysis while Economic Impacts, Socioeconomic Impacts, Public Policy impacts and environmental impacts are regarded as the dependent variables under analysis of the study.

(Habib et al., 2016) presents that projects under CPEC will enhance the business confidence in KPK and help in boosting the economic growth in KPK. Further it is argued that projects under CPEC will provide job opportunities in KPK and will increase the national and international economic competitiveness of KPK. (Mattson, 2011) also presents that CPEC projects will boost the manufacturing and service sector in KPK and will help in Job creation in the region. (Habib et al., 2016) further argues that in terms of socioeconomic impacts CPEC will improve the transportation facilities in the regions falling under the projects and also will have impacts on health and educational facilities in the region. The foreign investments in health and education will have far-reaching impacts, the material welfare will also have positive impacts and the poverty index in the region will fall. Hussain and Ali (2015) argue that CPEC will enhance the social infrastructure in the region and will help reducing poverty and income inequalities in the region.

(Xudong, 2015) comment that projects under CPEC have the potential will have positive impacts on the Public policy objectives of the people in the region to transfer the benefits of CPEC to future generation in Pakistan and will help Pakistan in efficient allocation of 
resources in KPK. (Haris, 2015) further argues that CPEC projects are sustainable and will also allow for women empowerment in the region, it is also suggested that projects under CPEC will change the government attitude towards development and stability in the country. The CPEC projects through influencing income level of the people and government developmental concerns can bring modernization in the region. In terms of environmental concerns it is argued by (Tong, 2015) that CO2 emission will be increased with the construction and transportation projects, the cutting of trees for the infrastructure will also influence the different species of plants and animals in the region.

\section{Hypothesis of the study}

Keeping in view the above theoretical grounds for the CPEC the study outlines the following hypothesis.

H1: CPEC will increase the economic growth and development in KPK

$\mathrm{H} 2$ : CPEC will have positive socioeconomic impacts in KPK

H3: The projects under CPEC will have positive impacts on Public Policy objectives in KPK

H4: CPEC will have negative Impacts on Environment in KPK

\section{Methodology}

In order to evaluate the impacts of CPEC on the different economic, socioeconomic, public policy and environmental indicators in KPK, the study uses a systematic analysis approach. The study works under the positivist ontology to find out the impacts of CPEC on different indicators in KPK and uses a deductive research approach. In terms of analysis the study uses quantitative tools for data collection and analysis for the research objectives of the study.

\subsection{Data of the Study}

For analyzing the objectives of the study the study used a survey strategy. The survey strategy of the study used self-administered questionnaire for collecting the primary data from respondents of the study. The items used in the questionnaire for analyzing the impacts of CPEC on different dependent variables in the study are adopted from (Hussain et al., 2015); (Hamid et al., 2012) and (Bengali, 2015). The questionnaire of the study consists of five different parts. The first part of the questionnaire collects demographic information of the respondents including the age, gender and income information. The second part of the questionnaire consists of 6 different items designed to collect data on the economic impacts of CPEC in KPK. The third part consists of 7 different items designed to collect data on the socioeconomic impacts of CPEC in KPK. The fourth and fifth section also consists of 6 items each for public policy impacts of CPEC and environmental impacts respectively. The factors of variables are given in following table of the study. 
Table 2. Factors of Variables

\begin{tabular}{|l|l|}
\hline \multicolumn{1}{|c|}{ Variables } & Code \\
\hline Economic Impacts (POC) & \\
\hline Business Confidence & EC1 \\
\hline Economic Growth & EC2 \\
\hline Economic Competitiveness & EC3 \\
\hline Job Creation & EC4 \\
\hline Manufacturing and service sector & EC5 \\
\hline Productivity & EC6 \\
\hline Socioeconomic Impacts & \\
\hline Transportation & SC1 \\
\hline Health Sector & SC2 \\
\hline Education & SC3 \\
\hline Real Estate Prices and Local People Welfare & SC4 \\
\hline Social Infrastructure & SC5 \\
\hline Poverty and Inequality & SC6 \\
\hline Public Policy Impacts & \\
\hline Economic assistance and Efficient Utilization & PP1 \\
\hline Sustainable and Transferable & PP2 \\
\hline Women Empowerment & PP3 \\
\hline Stability and Govt. Attitude & PP4 \\
\hline Modernization & PP5 \\
\hline Entrepreneurship & PP6 \\
\hline Environmental Impacts & \\
\hline Dust Emission & EN1 \\
\hline Plants and Animal Species & EN2 \\
\hline Noise Pollution & EN3 \\
\hline CO2 Emission & EN4 \\
\hline Loss of Agriculture Land & EN5 \\
\hline Industrial Wastes & EN6 \\
\hline & \\
\hline
\end{tabular}

\subsection{Data Reliability}

In order to analyze the reliability of the items used in the Questionnaire the study used the Chronbach`s Alpha technique as suggested by (Green et al., 1977); (Hair et al., 1998) (Downing, 2004). This technique is one of the most widely used for analyzing the presence of internal reliability among the items used in the questionnaire of the study.

\subsection{Sample of the Study}

The study for analyzing the impacts of CPEC used a purposive based sampling technique for selecting the sample of the study. The CPEC is a multidimensional project and has impacts on various aspects of the province and there are many segments of people who are influenced by the project. The purpose of the study is to find out the multidimensional impacts of CPEC 
and for the said reason a sample are selected comprising different sectors and segments of the province. The study selected the following organizations and Public policy departments for selecting the respondents of the study.

- Planning and Development Commission of Pakistan

- Pakistan Institute of Economic Development

- KPK IT Development Board

- Rural and Urban Development Department KPK

- Economic Zones Development Department KPK

- KP Bureau of Statistics

- Institute of Management Sciences Peshawar

- Institute of Management Studies Peshawar

The employees in these departments were selected in the sample of the study. Based on a convenience based sampling technique, questionnaire of the study were distributed and in some cases emailed to employees of these departments/ organizations. A final sample of 160 respondents was selected and their responses were analyzed.

\subsection{Data Analysis}

In order to analyze the responses collected through the questionnaire of the study the study used statistical analysis tools. The pie charts are used by the study for the description of demographic distribution of the respondents of the study. This study used the structure equation model (SEM) for analyzing the impacts of CPEC on the dependent variables of studies. StatSoft, (2011) presents that the SEM has two important analyses which include (1) Path Analysis (2) Regression analysis. The path analysis confirms the factors in the model and the confirmatory analysis of the Path analysis presents the goodness of fitness of the model. The regression analysis of the SEM analyzes the impacts of explanatory variable on the dependent variable in the study. In the first step of the structure equation model a theoretical model is developed based on the theoretical relationship of the variables under analysis. In the next step the goodness of fitness of the model is analyzed using the confirmatory factor analysis technique. For goodness of fitness of the model $\mathrm{Hu}$ and Bentler (1999), Byrne (1994, 2001), and Kline (1998) the value of $\frac{x^{2}}{d f}$ should be less than 3 . The other confirmatory analysis consists of CFI and RMSE values for the fitness of the model. The comparative fit index CFI presents that the CFI should be greater than .90 and a value close to .95 suggest a good fit. For goodness of fitness the parsimonious Fit index should be less than .08.The study used the SPSS AMOS for the structure equation model technique.

\section{Results and Discussion}

The questionnaire of the study was distributed among the sample of the study. The cronbach's alpha test presents coefficient higher than .70 for all the constructs implying internal reliability of the instrument. The primary data collected through the questionnaire was than analyzed using the different statistical tools results are presented in this section. 


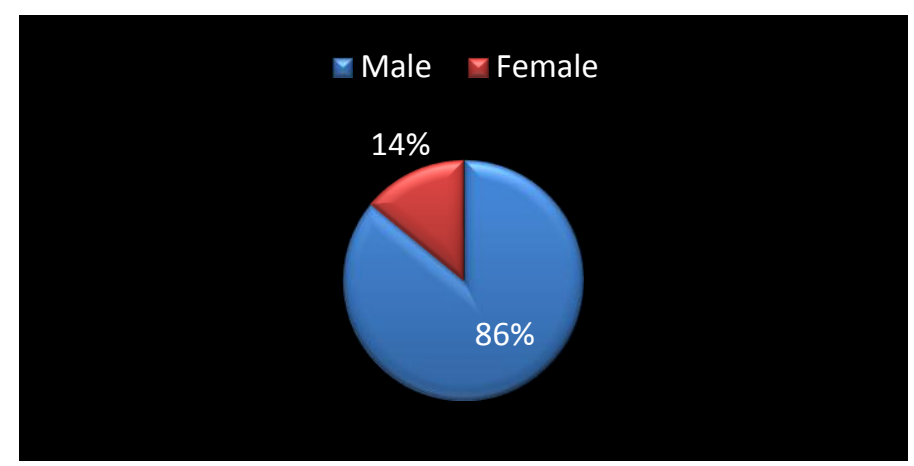

Figure 3. Gender

Figure 1 of the study presents the gender distribution of the respondents of the study which shows that $14 \%$ of the respondents are female while the remaining $86 \%$ are male respondents. This shows that women participation in the organization and education institutes in KPK is on the lower side.

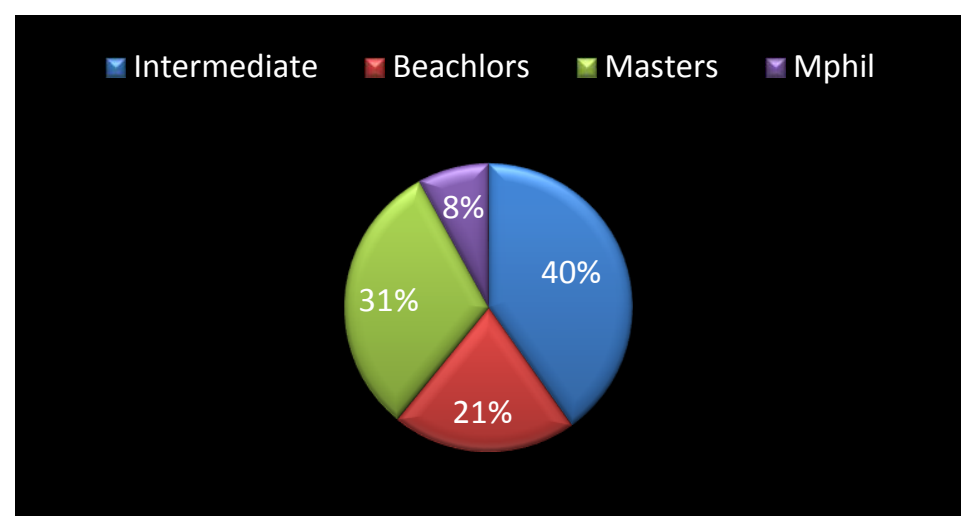

Figure 4. Qualification

The qualification of the respondents is given in figure 4 of the study and it can be observed from the chart that $40 \%$ of the respondents are intermediate while $37 \%$ are master or above qualified. This suggests that currently the educational qualification level of people in KPK is not very favorable. Figure 5 of the study presents the income level of people in KPK and from the figure it can be observed that almost $40 \%$ of the respondents fall in the income level of Rs.15k to Rs. 25. Only 3\% have an income higher than Rs 56,000 which also suggests that the income level of the people in the region is not very strong. 


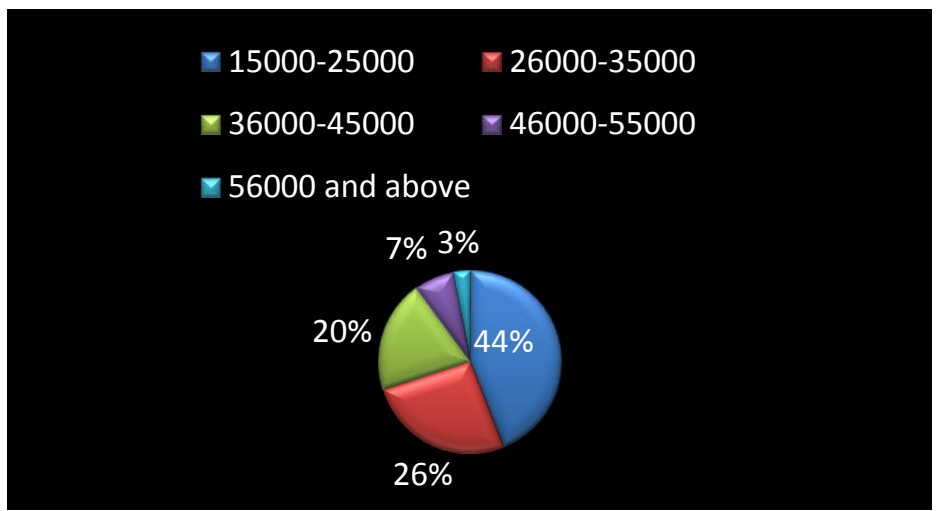

Figure 5. Income Level

\section{Confirmatory Factor Analysis}

The confirmatory factor analysis results of SEM are presented in Table.... Of the study. The table shows that the Chi square for the model is 180 with degrees of freedom of 78 thus the resultant $\frac{x^{2}}{d f}$ of the study is 2.307. As the value of $\frac{x^{2}}{d f}$ is less than 3 the thus implying the goodness of fitness of the overall model.

Table 3. (Default model)

\begin{tabular}{|l|}
\hline Minimum was achieved \\
\hline Chi-square $=180.207$ \\
\hline Degrees of freedom $=78$ \\
\hline Probability level $=.000$ \\
\hline$\frac{x^{2}}{d f}=2.307$ \\
\hline
\end{tabular}

The baseline comparison for the model is given in Table...of the study the CFI value in the table is 0.95 which further supports the fitness of the model as a value equal to or greater than 0.95 suggest fitness of the model.

Table 4. Baseline Comparisons

\begin{tabular}{|l|l|l|l|l|l|}
\hline Model & NFI Delta1 & RFI rho1 & IFI Delta2 & TLI rho2 & CFI \\
\hline Default model & .85 & .840 & .841 & .435 & .954 \\
\hline Saturated model & 1.000 & & 1.000 & & 1.000 \\
\hline Independence model & .000 & .000 & .000 & .000 & .000 \\
\hline
\end{tabular}

The RMSEA for the fitness of the structure model of the study is given in Table 5 of the study. The value for RMSE is 0.0159 which is less than .0159 suggesting the fitness of the structure equation of the model. 


\section{Macrothink

Table 5. RMSEA

\begin{tabular}{|l|l|l|l|l|}
\hline Model & RMSEA & LO 90 & HI 90 & PCLOSE \\
\hline Default model & .0159 & .149 & .170 & .000 \\
\hline Independence model & .212 & .203 & .222 & .000 \\
\hline
\end{tabular}

\section{Hypothesis Testing with Structure Equation Modeling}

The results of SEM are given in Table 6 shows the regression estimate of the dependent variables of the study. The individual slope coefficients of the unobserved variables and their factors are given in figure 3 of the study. The path diagram given below also presents the coefficients for all the observed and unobserved variables in the analysis. The slope coefficient for Economic impacts is .523 and is significant at 5\% level of significance. The table above shows that the $\mathrm{P}$ value for all the six aspects of economic impacts is less than 5\% level of significance with $\mathrm{P}<.01$ for all the six economic aspects suggest significant impacts of CPEC on economic development in KPK. The significance of P values implies that CPEC will help in boosting the business confidence in KPK and will help in boosting economic growth in KPK thereby enhancing the regional and international competitiveness of different industries. 


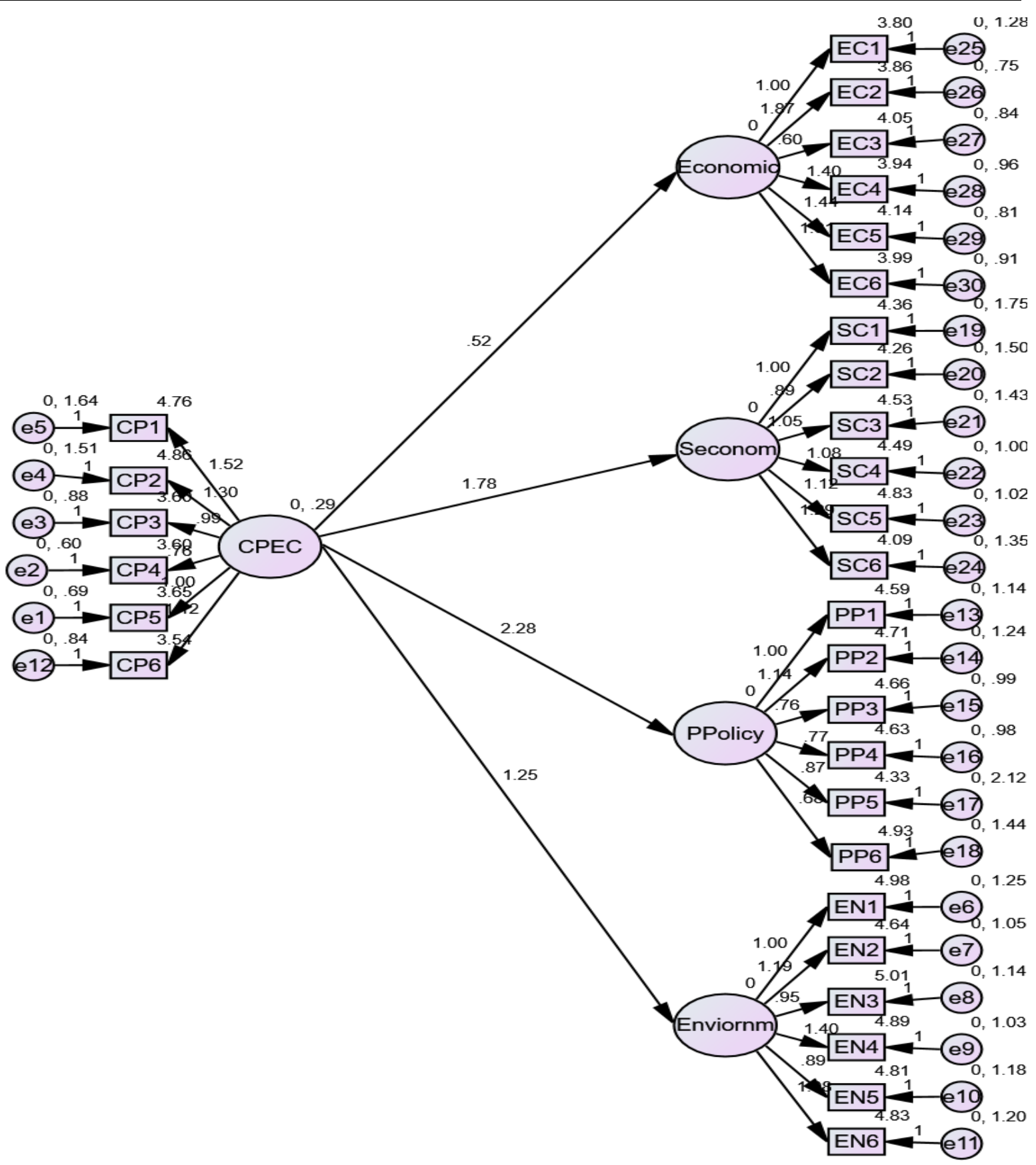

Figure 3. Path Analysis Diagram

The results also imply that CPEC will have positive impacts on service and manufacturing industry that will increase the job opportunities and also increase productivity of the province. These results support the stance of (Habib et al., 2016) who presents that projects under CPEC will enhance the business confidence in KPK and help in boosting the economic growth in KPK.

The slope coefficient for socioeconomic impacts is 1.782 and is significant at $1 \%$ level of significance. In the table it can be seen that $\mathrm{T}$ values for all the socioeconomic dimensions are greater than the critical value required for significance. The socioeconomic dimensions in the table are significant at $\mathrm{P}<.01$. The result of SEM thus implies that CPEC will improve the 
road and rail transportation structure in KPK. The foreign investment in health and education sector will further improve the education and health dimension of society in KPK. The real estate prices of KPK will increase that will have positive financial impacts of CPEC on local people in KPK. The results also suggest that CPEC projects will improve the social infrastructure in KPK and will reduce the poverty and income inequality in KPK as suggested by (Habib et al., 2016) who argues that in terms of socioeconomic impacts CPEC will improve the transportation facilities in the regions falling under the projects and also will have impacts on health and educational facilities in the region.

The slope coefficient for Public Policy impacts of CPEC in KPK is 2.277 and is significant at $1 \%$ level of significance. In the table it can be seen that $\mathrm{P}$ value for all the Public Policy dimensions in the table are lower than the $\mathrm{P}$ value required for the significance of mean difference from zero. This implies that all the mean differences for all the Public Policy concerns in the table are significant at $\mathrm{P}<.01$. This implies that the projects under CPEC will promises sustainability and will help in efficient utilization of resources and will boost the economic assistance.

The results also suggest that the respondents suggest that project under CPEC are sustainable and the benefits can be transferred to the future generation of KPK. The economic zones, entrepreneurship and job opportunities will increase the women participation and increase women empowerment in KPK. The results presented in the table supports the point that CPEC will bring about political and economic stability in the region and will also help in shaping a positive attitude of the government towards socioeconomic development in the area. The results also suggest that CPEC will help in modernization of the region and will provide further entrepreneurship opportunities in the region. The results are in line with the study of (Xudong, 2015) who comments that projects under CPEC have the potential will have positive impacts on the Public policy objectives of the people in the region to transfer the benefits of CPEC to future generation in Pakistan and will help Pakistan in efficient allocation of resources in KPK. The slope coefficient for environmental impacts in the Table is -1.248 with $\mathrm{P}$ value significant at $\mathrm{P}<.01$. This implies that the CPEC will have negative impacts on environment in KPK. The $\mathrm{P}$ values for all the dimensions of environmental are also significant at $\mathrm{P}<.01$.

Table 6. Regression Estimates

\begin{tabular}{|l|l|l|l|c|c|c|c|}
\hline & & & Estimate & S.E. & C.R. & P & Label \\
\hline Economic & $<---$ & CPEC & $\mathbf{. 5 2 3}$ & $\mathbf{. 2 6 4}$ & $\mathbf{1 . 9 8 3}$ & $* * *$ & par_26 \\
\hline Seconom & $<---$ & CPEC & $\mathbf{1 . 7 8 2}$ & $\mathbf{. 4 3 8}$ & $\mathbf{4 . 0 7 3}$ & $* * *$ & par_27 \\
\hline PPolicy & $<---$ & CPEC & $\mathbf{2 . 2 7 7}$ & $\mathbf{. 4 7 6}$ & $\mathbf{4 . 7 8 6}$ & $* * *$ & par_28 \\
\hline Enviornm & $<---$ & CPEC & $\mathbf{- 1 . 2 4 8}$ & $\mathbf{. 3 3 6}$ & $\mathbf{3 . 7 1 6}$ & $* * *$ & par_29 \\
\hline CP5 & $<---$ & CPEC & 1.000 & & & & \\
\hline CP4 & $<---$ & CPEC & .762 & .216 & 3.535 & $* * *$ & par_1 \\
\hline CP3 & $<---$ & CPEC & .991 & .269 & 3.679 & $* * *$ & par_2 \\
\hline CP2 & $<---$ & CPEC & 1.300 & .359 & 3.619 & $* * *$ & par_3 \\
\hline
\end{tabular}




\begin{tabular}{|l|l|l|l|c|c|c|c|}
\hline & & & Estimate & S.E. & C.R. & P & Label \\
\hline CP1 & $<---$ & CPEC & 1.523 & .397 & 3.837 & $* * *$ & par_4 \\
\hline EN1 & $<---$ & Enviornm & 1.000 & & & & \\
\hline EN2 & $<---$ & Enviornm & 1.191 & .291 & 4.095 & $* * *$ & par_5 \\
\hline EN3 & $<---$ & Enviornm & .949 & .258 & 3.678 & $* * *$ & par_6 \\
\hline EN4 & $<---$ & Enviornm & 1.401 & .324 & 4.319 & $* * *$ & par_7 \\
\hline EN5 & $<---$ & Enviornm & .887 & .254 & 3.490 & $* * *$ & par_8 \\
\hline EN6 & $<---$ & Enviornm & 1.082 & .283 & 3.824 & $* * *$ & par_9 \\
\hline CP6 & $<---$ & CPEC & 1.123 & .284 & 3.959 & $* * *$ & par_10 \\
\hline PP1 & $<---$ & PPolicy & 1.000 & & & & \\
\hline PP2 & $<---$ & PPolicy & 1.138 & .154 & 7.400 & $* * *$ & par_11 \\
\hline PP3 & $<---$ & PPolicy & .762 & .122 & 6.271 & $* * *$ & par_12 \\
\hline PP4 & $<---$ & PPolicy & .771 & .123 & 6.267 & $* * *$ & par_13 \\
\hline PP5 & $<---$ & PPolicy & .870 & .164 & 5.295 & $* * *$ & par_14 \\
\hline PP6 & $<---$ & PPolicy & .675 & .139 & 4.875 & $* * *$ & par_15 \\
\hline SC1 & $<---$ & Seconom & 1.000 & & .767 & & \\
\hline SC2 & $<---$ & Seconom & .889 & .207 & 4.294 & $* * *$ & par_16 \\
\hline SC3 & $<---$ & Seconom & 1.047 & .222 & 4.722 & $* * *$ & par_17 \\
\hline SC4 & $<---$ & Seconom & 1.077 & .211 & 5.105 & $* * *$ & par_18 \\
\hline SC5 & $<---$ & Seconom & 1.115 & .219 & 5.092 & $* * *$ & par_19 \\
\hline SC6 & $<---$ & Seconom & 1.288 & .249 & 5.162 & $* * *$ & par_20 \\
\hline EC1 & $<---$ & Economic & 1.000 & & & & \\
\hline EC2 & $<---$ & Economic & 1.865 & .943 & 1.978 & $* * *$ & par_21 \\
\hline EC3 & $<---$ & Economic & .601 & .471 & 1.275 & $* * *$ & par_22 \\
\hline EC4 & $<---$ & Economic & 1.399 & .767 & 1.824 & $* * *$ & par_23 \\
\hline EC5 & Economic & 1.438 & .765 & 1.879 & $* * *$ & par_24 \\
\hline EC6 & Economic & 1.813 & .932 & 1.945 & $* * *$ & par_25 \\
\hline
\end{tabular}

The Dust Emission is significant at $\mathrm{P}<.01$ which implies that the respondents believe that CPEC will increase the dust emission with the construction of economic zones and roads infrastructure. The results however show that CPEC will not have significant impacts on the plants and animal species falling under the route. The table shows that respondents believe that CPEC will increase the Noise Pollution in the area and also will increase the CO2 emission due to the new industries and increased traffic. The results further suggest that the loss of agriculture land is not significant. The results however suggest that Industrial waste will increase due to the industrial development. Such concerns are also highlighted by (Tong, 2015,pp.56) suggesting that $\mathrm{CO} 2$ emission will be increased with the construction and transportation projects and the emission of dust and industrial waste will also rise. 


\section{Conclusion}

In the recent era of globalization, bilateral trade agreements, transit trade and market liberalization the regional cooperation hold a significant importance to the development of the underdeveloped regions of the world. The Pak China friendship has benefited Pakistan and China for the last few decades and China has effectively used the geographical presence of Pakistan for its international outreach. The CPEC project is one such initiative to integrate Chinese market to international destination at cost effective route. Beside the CPEC advantages to China the projects under CPEC holds significant importance to the underdeveloped region of Pakistan and the Pakistani Economy. The investment from China in infrastructure energy sector will significantly boost the socioeconomic and Public policy objectives and indicators of Pakistan. The study analyzed the economic, socioeconomic and public policy impacts of CPEC in KPK Pakistan. The results support the point that Economic Zones, Energy Projects and Infrastructure under CPEC holds significant importance to the Economic activity and confidence building in KPK. The project will positively influence the health and education sector and will promise new job and entrepreneurship opportunities in KPK. It is also expected to increase the women participation and empowerment in the country. The quality of life and material welfare of the people along with economic and political stability in the region is also expected to boost with the projects under CPEC.

\section{References}

Abid, M., \& Ashfaq, A. (2015). CPEC: Challenges and Opportunities for Pakistan. Pakistan Vision, 16(2).

Aqeel, M. (2016). Impact of China Pakistan Economic Corridor. Unpublished degree thesis, BBA International Business. ARCADA. pp.106

Alkire, S., Foster, J., Seth, S., Santos, M. E., Roche, J. M., \& Ballon, P. (2015). Multidimensional Poverty Measurement and Analysis. Oxford University Press. https://doi.org/10.1093/acprof:oso/9780199689491.001.0001

Armstrong, J. S. (2001). Principles of Forecasting: A Handbook for Researchers and Practitioners. Norwell, Massachusetts: Kluwer Academic Publishers.

https://doi.org/10.1007/978-0-306-47630-3

Bengali, K. (2015). China-Pakistan Economic Corridor? The Route Controversy, Chief Minister's Policy Reform Unit, Government of Balochistan, pp.133

Bhattacharyay, B. N., Masahiro, K., \& Raiat, N. (2012). Infrastructure for Asian, pp.223. https://doi.org/10.4337/9781781003138

Connectivity. Asian Development Bank Institute. BISP (2016). Poverty Profile. Population of Pakistan: An Analysis of NSER 2010-11.

Benazir Income Support Programme (BISP).

BISP (2016). Youth and Employment Participation. Population of Pakistan: An Analysis of NSER 2010-11. Benazir Income Support Programme (BISP). 
CID (2016). Center for International Development at Harvard University (CID). pp.304

Hussain, E., \& Ali, G. (2015). China-Pakistan Economic, Daily Times, accessed February 28, 2015, pp.117.

http://www.dailytimes.com.pk/opinion/28-Feb-2015/pakistan-Chinaeconomic-relations

Gilbert, J., \& Nilanjan, B. (2012). Socio-economic Impact of Regional Transportation Infrastructure in South Asia. Edited, Infrastructure for Asian Connectivity. Asian Development Bank Institute, pp.203. https://doi.org/10.4337/9781781003138.00013

Goldstein, A. (2005). Rising to the Challenge: China's Grand Strategy and International Security. Stanford University Press.

Habib, S, Fazal, R. Farkhanda, J., \& Adeel, K. (2015). Assessing Ex-ante Socioeconomic. 205

Impact of China Pakistan Economic Corridor (CPEC) Across the Zone of Influence. Proceedings of International Conference on CPEC, GC University, Lahore. December 09-10.

Hamid, N., \& Sarah, H. (2012). The Opportunities and Pitfalls of Pakistan's Trade with China and Other Neighbors. The Lahore Journal of Economics, 154

Haq, R., \& Zia, U. (2013) Multidimensional Wellbeing: An Index of Quality of Life in a Developing Economy. Social Indicator Research, 114(3).

Haris, M. (2015). Identifying investment sectors along Pak China economic corridor, Memoir of International Academic Symposium on China Pakistan Economic Corridor, 39-45.

Hyndman, R. J. (2014). Forecasting: Principles and Practice. University of Western Australia.

Maggino, F., \& Zumbo, B. D. (2012). Measuring the quality of life and the construction of social indicators. In K. C. Land, A. C. Michalos, \& M. J.Sirgy, eds. Handbook of social indicators and quality of life research, Springer, 201-238.

https://doi.org/10.1007/978-94-007-2421-1_10

Mattson, J. (2011). Transportation, distance, and health care utilization for older adults in rural and small urban areas. Transportation Research Record: Journal of the Transportation Research Board, 192-199. https://doi.org/10.3141/2265-22

Midgley, J. (2013). Social Development: Theory and Practice. London: SAGE, pp.84

Murtagh, F., \& Heck, A. (1987). Multivariate Data Analysis. D. Reidel, Netherlands. https://doi.org/10.1007/978-94-009-3789-5

Nau, R. (2014). Review of Basic Statistics and the Simplest Forecasting Model: The Sample Mean. Fuqua School of Business, Duke University.

Pakistan, Government of. (2015). The Pakistan Social and Living Standards Measurement (PSLM) Survey 2014-15. Pakistan Bureau of Statistics, Islambad.

Pakistan, Government of. (2016). Multidimensional Poverty in Pakistan. Ministry of Planning, 


\section{Macrothink \\ Environmental Management and Sustainable Development \\ ISSN 2164-7682 2019, Vol. 8, No. 1}

Development and Reforms. Pakistan.

Shakeel, A. R. (2015). China Pakistan Economic Corridor-A Chinese Dream Being materialized through Pakistan, SDPI.

Small, A. (2015). The China Pakistan Axis: Asia' New Geopolitics. Oxford University Press, pp.185. https://doi.org/10.1093/acprof:oso/9780190210755.001.0001

Tong, L. (2015). CPEC Industrial Zones and China Pakistan Capacity, Cooperation. pp.56 http://issi.org.pk/wp-content/uploads/2015/12/Liang-Tong_3435_SS_41_20142015.pdf

UNDP (1990). Human Development Report 1990. The United Nations Development Programme (UNDP).

UNDP (2014) Sustaining Human Progress Reducing Vulnerabilities and Building Resilience; Technical notes. Human Development Report 2014. The United Nations Development Programme (UNDP), One United Nation Palaza, New York.

UNDP (2015). Work for Human Development, Human Development Report 2015. The United Nations Development Programme (UNDP), One United Nation Palaza, New York, NY 10017.

Howard, W., \& Edoardo, M. (2004). Books, buildings, and learning outcomes: An impact evaluation of World Bank support to basic education in Ghana. (Washington DC: World Bank, 2004).

Xudong, Z. (2015). China Today, February, 41-43.

\section{Copyright Disclaimer}

Copyright for this article is retained by the author(s), with first publication rights granted to the journal.

This is an open-access article distributed under the terms and conditions of the Creative Commons Attribution license (http://creativecommons.org/licenses/by/3.0/). 